\title{
DIÁLOGOS EM AMBIENTE E SOCIEDADE: ENTREVISTA COM O PROFESSOR LÚCIO JOSÉ SOBRAL DA CUNHA (UNIVERSIDADE DE COIMBRA, PORTUGAL)
}

Jorge Luís de Oliveira Pinto Filho ${ }^{1}$

Resumo: Este trabalho objetiva relatar uma entrevista do Professor Lúcio José Sobral da Cunha (Universidade de Coimbra) ao Professor Jorge Luís de Oliveira Pinto Filho (UFERSA) sobre a questão ambiental contemporânea e o papel da Universidade neste debate. Para isso, a entrevista foi realizada em Coimbra, Portugal durante um Estágio Pós Doutoral do Professor Jorge Pinto Filho sob orientação do Professor Lúcio Cunha. Inicialmente, abordou os seguintes aspectos: as relações ambiente e sociedade; a crise ambiental; os debates ambientais; as políticas ambientais $\mathrm{e}$; as dimensões da gestão ambiental e, sua a operacionalização. Posteriormente, enalteceu os temas: as pesquisas multidisciplinares; a função da universidade no Século XXI e; as universidade emergentes e o desenvolvimento regional. Portanto, a entrevista permitiu evidenciar a questão ambiental contemporânea e o papel da Universidade neste debate.

Palavras-chave: Questão ambiental contemporânea. Crise ambiental. Políticas públicas ambientais. Gestão ambiental.

\section{DIALOGUES IN ENVIRONMENT AND SOCIETY: INTERVIEW WITH PROFESSOR LÚCIO JOSÉ SOBRAL DA CUNHA (UNIVERSITY OF COIMBRA, PORTUGAL)}

Abstract: This paper aims to report an interview of Professor Lúcio José Sobral da Cunha (University of Coimbra) to Professor Jorge Luís de Oliveira Pinto Filho (UFERSA) on the contemporary environmental issue and the role of the University in this debate. For this, the interview was conducted in Coimbra, Portugal during a Post Doctoral Internship of Professor Jorge Pinto Filho under the guidance of Professor Lúcio Cunha. Initially, it addressed the following aspects: environmental and society relations; the environmental crisis; environmental debates; environmental policies and; the dimensions of environmental management and its operationalization. Later, he praised the themes: multidisciplinary research; the role of the university in the $21 \mathrm{st}$ century and; emerging university and regional development. Therefore, the interview showed the contemporary environmental issue and the role of the University in this debate.

Keywords: Contemporary environmental issue. Environmental crisis. Environmental public policies. Environmental management.

\section{DIÁLOGOS EN MEDIO AMBIENTE Y SOCIEDAD: ENTREVISTA CON EL PROFESOR LÚCIO JOSÉ SOBRAL DA CUNHA (UNIVERSIDAD DE COIMBRA, PORTUGAL)}

Resumen: Este trabajo tiene como objetivo informar de una entrevista del profesor Lúcio José Sobral da Cunha (Universidad de Coimbra) al profesor Jorge Luís de Oliveira Pinto Filho (UFERSA) sobre el tema ambiental contemporáneo y el papel de la Universidad en este debate. Para ello, la entrevista se realizó en Coimbra,

${ }_{1}$ Universidade Federal Rural do Semiárido (UFERSA), Departamento de Engenharias e Tecnologia Pau dos Ferros, Brasil, jorge.filho@ufersa.edu.br, https://orcid.org/0000-0002-2730-6929 
Portugal, durante una pasantía postdoctoral del profesor Jorge Pinto Filho bajo la dirección del profesor Lúcio Cunha. Inicialmente, abordó los siguientes aspectos: relaciones ambientales y de la sociedad; la crisis ambiental; debates ambientales; políticas ambientales $\mathrm{y}$; las dimensiones de la gestión ambiental y su operacionalización. Más tarde, elogió los temas: investigación multidisciplinaria; el papel de la universidad en el siglo XXI y; universidad emergente y desarrollo regional. Por lo tanto, la entrevista mostró el tema ambiental contemporáneo y el papel de la Universidad en este debate.

Palabras clave: Cuestión ambiental contemporánea. Crisis ambiental. Políticas públicas ambientales. Gestión ambiental.

\section{Apresentação}

A partir do projeto de pesquisa ANÁLISE COMPARATIVA DE GESTÃO DE RECURSOS HÍDRICOS EM PORTUGAL E NO BRASIL: estudo do caso da Administração da Região Hidrográfica - ARH do Centro (Portugal) e da Bacia Hidrográfica do Rio Apodi-Mossoró (Brasil), realizado entre a Universidade de Coimbra, especificamente o Centro de Estudos de Geografia e Ordenamento do Território - CEGOT e a UFERSA, especialmente o Centro Multidisciplinar de Pau dos Ferros - CPMF, através da realização de um Estágio Pós Doutoral do Professor Adjunto Jorge Luís de Oliveira Pinto Filho (UFERSA) sob orientação do Professor Catedrático Lúcio José Sobral da Cunha (Universidade de Coimbra), desenvolveu-se a ideia de tecer debates sobre a questão ambiental contemporânea.

O Professor Jorge Luís de Oliveira Pinto Filho é Técnico em Saneamento pelo CEFET-RN (2005-2007), Bacharel em Gestão Ambiental pela Universidade do Estado do Rio Grande do Norte-UERN (2003-2007), Mestre em Ciências do Solo pela UFERSA (2008-2010), Doutor em Desenvolvimento e Meio Ambiente pela Universidade Federal do Rio Grande do Norte-UFRN (2012-2016), com período sanduíche em Technische Universität Bergakademie Freiberg-TUBF (2014-2015) sob orientação de Jörg Matschullat e Pós Doutor pelo Centro de Estudos de Geografia e Ordenamento do Território - CEGOT da Universidade de Coimbra (2019-2020), sob supervisão de Lúcio Cunha. Atualmente é Professor Adjunto do Departamento de Engenharias e Tecnologia-DETEC, do CMPF (UFERSA), onde ministra as disciplinas de Ambiente, Energia e Sociedade, Recuperação de Áreas Degradadas, Sistema de Gestão Ambiental e Direito Ambiental; Pesquisador Permanente no Programa de Pós-Graduação em Planejamento e Dinâmicas Territoriais do Semiárido-PLANDITES (UERN), atuando na linha de pesquisa de Dinâmicas Territoriais no Semiárido; e com atuação de profissional no âmbito de Gestão Ambiental Empresarial. 
O Professor Lúcio José Sobral da Cunha é doutor (1989) com agregação (2002) em Geografia (Geografia Física). É Professor Catedrático, Director do Departamento de Geografia e Turismo da Faculdade de Letras da Universidade de Coimbra e investigador do CEGOT das Universidades de Coimbra e Porto, onde coordena o grupo I - Natureza e Dinâmicas Ambientais. Tem experiência na área de Geociências, com ênfase em Geografia Física e, particularmente, nas áreas de Geomorfologia (Geomorfologia cárstica, Geomorfologia fluvial, Riscos geomorfológicos e Património geomorfológico), Geoprocessamento aplicado ao Ordenamento do Território e Geografia Física Aplicada.

Sendo assim, o presente documento tem como objetivo relatar uma entrevista do Professor Lúcio José Sobral da Cunha (Universidade de Coimbra) ao Professor Jorge Luís de Oliveira Pinto Filho (UFERSA) sobre a questão ambiental contemporânea e o papel da Universidade neste debate.

\section{Entrevista com o professor Lúcio Cunha (Universidade de Coimbra)}

\section{A contradição nas relações Ambiente e Sociedade}

Jorge Pinto Filho - Prof. Lúcio Cunha, gostaria que você iniciasse explicando qual sua leitura sobre a relação entre ambiente e sociedade ao longo dos anos, passando pela Antiguidade (400 a.C. - 476), Idade Média (476 - 1453), Idade Moderna (1453 - 1789) e Idade Contemporânea (a partir de 1789)?

Ao longo do tempo que o Ser Humano leva na superfície da Terra a sua relação com o ambiente foi quase sempre uma relação relativamente conflituosa. Se, inicialmente, nos tempos pré-históricos o papel do ambiente foi principalmente o de fornecedor de recursos básicos para a vida humana (ar, água, alimentação, abrigo, vestuário, utensílios), a partir do Neolítico, com o progressivo sedentarismo, com o aparecimento da agricultura e a domesticação dos animais, iniciam-se os chamados impactes ambientais, ainda que mais relacionados com os processos de utilização do ambiente natural (recoleção; caça; pastorícia) do que propriamente com os processos de eliminação dos dejetos da utilização dos recursos ambientais. Do Neolítico até aos nossos dias, a relação entre a Sociedade e o seu Ambiente não tem parado de se incrementar, quer do ponto de vista extrativo, quer do ponto de vista da poluição ambiental pelos processos de retorno à Natureza das sobras e dos produtos transformados pela utilização humana. A Natureza biótica e abiótica e, num sentido mais geral, o Ambiente, adquirem progressivamente uma importância 
utilitária, económica e social, um significado cultural, por vezes quase religioso, e uma presença constante na vida humana.

Sabemos que os processos evolutivos da Sociedade não acontecem de modo paulatino e contínuo, mas que há fases muito mais rápidas que outras no que respeita a estes processos evolutivos. Assim, fases como a Antiguidade Clássica, o início da Época Moderna, a Revolução Industrial, ou o grande boom industrial do pós-Guerra, estão marcadas na História não só pelo seu significado económico, social e cultural, mas também, em grande parte, pelas modificações que introduziram na relações dos Seres Humanos com o seu Ambiente.

Dois exemplos apenas: os processos dos chamados Descobrimentos (a primeira ou segunda fase de um processo de globalização das economias e das culturas) ficou fortemente marcado em Portugal e Espanha por fortes impactes sobre a floresta, relacionados com a construção naval, e por impactes bem maiores nos ambientes Africano e Americano, onde se iniciou um processo de delapidação das riquezas naturais e de degeneração cultural dos povos indígenas, que se foi prolongando depois ao longo dos tempos; o início da Época Contemporânea aconteceu com a Revolução Francesa, mas foi acompanhado da chamada "Revolução Industrial" que permitiu um forte desenvolvimento económico e social, com base no desenvolvimento da máquina a vapor (força motriz do carvão), mas também provocou uma forte poluição do ar nas áreas industriais e depois, também, nas áreas urbanas, nas águas e nos solos), hoje referida como o marco inicial do processo de alterações climáticas, porventura o processo mais preocupante de alteração ambiental que estamos a viver.

\section{A Crise Ambiental e o nosso futuro}

Jorge Pinto Filho - Prof. Lúcio Cunha, a partir desse cenário de transformação do ambiente pela sociedade através do crescimento exponencial da população, da maior demanda de consumo dos recursos naturais e dos processos de poluição e contaminação ambiental, geraram-se profundas e irreversíveis consequências, que resultaram na crise ambiental, como vê você este cenário?

A grande maioria das ações de transformação do ambiente pela sociedade tem a ver com o uso, poderíamos mesmo dizer com a exploração, dos territórios e do ambiente para fins económicos. A economia está omnipresente no modo de pensar e viver em sociedade, por isso não é admirar que os velhos recursos tenham hoje uma importância e mesmo um valor renovados, como acontece com a água, com o 
clima, com o solo, com a biodiversidade e com a geodiversidade. Ao mesmo tempo a evolução tecnológica, em vez de caminhar no sentido da redução na extração de recursos não renováveis como os combustíveis fósseis, os minerais metálicos e não metálicos e as madeiras, parece estar todos os dias a encontrar novos produtos para extrair, como tem acontecido em Portugal, com a questão do Lítio.

Finalmente, a extração e o consumo dos recursos tem uma geografia por vezes muito desigual e injusta, com os países pobres a produzir e os países ricos a transformar, a negociar e a consumir. Também no que diz respeito à poluição associada a este consumo desenfreado a geografia é desigual e injusta, seja no que se refere à forte poluição da água e do ar associada à extração, seja mesmo no que se refere ao impacto diferenciado das chamadas alterações climáticas, a resultante maior da poluição do ar nos séculos XX e XXI.

Claro que devemos ter esperança no futuro! Hoje discute-se muito a economia verde e a economia circular. Os vários R's da reutilização, redução, reciclagem, reintegração e reparação, são motivos de esperança, assim como a consciência cada vez mais generalizada da importância e mesmo do valor económico dos serviços ecossistêmicos ligados ao ambiente (provisão, regulação, suporte e culturais). Mas quem os paga? Como se pagam? Quem os pode pagar? Quem tem obrigação de os pagar e a quem? Muitas vezes, fica-me a sensação que este discurso verde, ou tão só enverdecido, mais não é que uma grande manobra publicitária no sentido de, ao mesmo tempo que nos incentiva a um consumo desenfreado, confortar a nossa consciência ambiental, enquanto seres humanos dependentes de uma Natureza, à qual pertencemos e que também somos.

\section{Os debates ambientais e uma nova consciência ecológica}

Jorge Pinto Filho - Prof. Lúcio Cunha, diante desse quadro evolutivo da atual crise de paradigma, gostaria que você explicasse qual sua compreensão sobre os debates ambientais da atualidade?

Como referi no ponto anterior, o debate ambiental atual parece-me um tanto distorcido da realidade. Por vezes essa distorção decorre apenas de diferentes percepções dos problemas ambientais e das suas possíveis soluções por parte dos diferentes intervenientes nos debates. Outras vezes o debate fica distorcido pela importância e pela força relativas dos intervenientes, sobretudo pelo valor económico das ideias em debate. Voltando, por exemplo, a uma das bandeiras ambientais à escala dos municípios e das famílias, a bandeira da reciclagem. Em 
termos muito gerais, os resultados da reciclagem do vidro, do papel e das embalagens de cartão, plástico e metal fica, quase sempre, muitíssimo aquém do esforço feito pela população que absorveu completamente a justeza da ideia e que transporta, de forma quase religiosa, os seus lixos para os pontos de recolha, os famosos ecopontos.

No momento atual, o grande debate em curso é o debate em torno das alterações climáticas, suas causas, consequências, medidas de mitigação e adaptação. Trata-se de um debate importante, também com muita Geografia à mistura. De um lado, os que pensam que temos de mitigar as Alterações Climáticas, reduzir o aquecimento a menos de $1,5^{\circ} \mathrm{C}$ até final do século $\mathrm{XXI}$, impedir uma subida significativa do nível dos oceanos, estão as grandes organizações mundiais, como a ONU, alguns países mais desenvolvidos, em regra aqueles que agora menos têm a ganhar com a indústria do petróleo, e os países menos desenvolvidos que se sentem mais ameaçados pelas consequências das Alterações Climáticas. Mas do outro, abertamente ou de modo algo escondido, estão os grandes países da economia do petróleo e/ou do carvão, os países em desenvolvimento que pretendem crescer, mas não têm disponibilidade financeira nem recursos mobilizáveis. E neste jogo se vão fazendo compromissos internacionais, políticas de blocos, diplomacias! O problema é que esta questão não é uma questão de negociação e de compromissos, mas sim uma questão de atuação firme e de curto prazo.

Por outro lado, enquanto a nível geral, global, político e económico as Alterações Climáticas são mais ou menos levadas a sério, a nível local, onde se situam as intervenções dos cidadãos, as Alterações Climáticas não só não são levadas a sério (quantos de nós somos capazes de prescindir do automóvel particular?), como muitas vezes são utilizadas como pretexto para desculpar erros de ordenamento do território, obras mal feitas, gastos mal direcionados: basta pensar na importância que é dada no meu país à justificação do flagelo dos incêndios florestais de Verão, muito mais em termos climáticos (as Alterações Climáticas são o bode expiatório) do que em termos de gestão florestal.

\section{Políticas ambientais e o caminho para sustentabilidade}

Jorge Pinto Filho - Prof. Lúcio Cunha, com a discussão ambiental ganhando notoriedade, como você avalia as agendas públicas sobre meio ambiente e as políticas ambientais do setor privado? 
Se quisermos ser politicamente corretos, deveremos dizer que os setores público e privado são os dois pratos da balança do desenvolvimento e do bem estar dos cidadãos. Ao poder público, aos governos centrais e locais compete a definição de políticas gerais e setoriais e das estratégias a seguir para as alcançar, enquanto que ao sector privado deveria competir a execução prática dessas estratégias de desenvolvimento (criação de infraestruturas; produção e distribuição de bens e serviços). Por vezes, ou nalguns países, atribui-se também ao setor público a produção e distribuição de determinados serviços e bens, particularmente, quando estes se revestem de elevado valor estratégico (ex: bens militares) ou correspondem a bens essenciais para a população e devem chegar a todos (educação, saúde, cultura, ambiente). É isso que acontece em Portugal e, na minha opinião, o setor público tem um importante papel a desempenhar também no sector ambiental. No entanto não podemos esquecer que o setor público tem como objetivo central das suas ações o bem estar dos vários estratos da população, ou, se preferirmos, da sociedade e dos eleitores, enquanto o sector privado tem sempre como objetivo principal o lucro para os acionistas das grandes companhias ou para os patrões das menores. No mundo liberal em que vivemos, muitas vezes se entende que o setor público é difícil de gerir, pois tem de seguir regras mais restritas e tem de prestar contas à muitas instituições, coisa que não acontece com o setor privado. Por isso muitas vezes se estabelecem, e isso acontece muito com as atividades económicas ligadas ao ambiente, um conjunto de (pseudo)privatizações, com a criação de empresas de gestão privada para gerir bens públicos, como tem acontecido com as empresas ligadas à distribuição de água ou de gestão do saneamento ou dos lixos urbanos. A eficácia desta compartimentação de responsabilidades e de atuações dos sectores público e privado no âmbito das políticas ambientais está ainda por avaliar. Seja como for, é necessário que os objetivos estejam bem estabelecidos, que as avaliações sejam feitas regularmente e que as responsabilidades pelo que bem e de mal está a ser concretizado sejam permanentemente escrutinadas e não apenas quando surgem grandes escândalos.

Penso que enquanto houver financiamentos significativos a chegar da União Europeia há vantagens para todos, para o sector público que não pode chegar a tudo o que é necessário fazer e ao sector privado que vai obtendo os seus lucros, quase sempre às custas de investimentos públicos... Depois, veremos...

No que diz respeito ao caminho para a sustentabilidade, importa saber de que sustentabilidade se trata. O termo desenvolvimento sustentável surge em 1987 
através do trabalho "O nosso futuro comum", que basicamente corresponde a um relatório da Comissão Mundial para o Ambiente e Desenvolvimento, presidida pela Senhora Gro Bruntland, embora muitas das preocupações nele expressas viessem já dos anos setenta e da convicção de que o desenvolvimento económico do período do pós-guerra estava a provocar o esgotamento dos recursos do Planeta e a comprometer o futuro de quem o habitava. Assim, o conceito central de desenvolvimento sustentável é "o desenvolvimento que satisfaz as necessidades da geração presente sem comprometer a capacidade das gerações futuras para satisfazerem as suas próprias necessidades". E este tipo de desenvolvimento tinha como pólos contrários, que era necessário articular, o Desenvolvimento (a Economia) e os Recursos do Planeta (o Ambiente). A ideia de sustentabilidade foi tão forte, tão inteligente, tão assertiva, que rapidamente foi apropriada por diferentes sectores da sociedade e dos dois pólos que era necessário compatibilizar, passámos para $3,4,5,6 \ldots$ (para além do ambiente e da sociedade - economia, passámos a integrar na equação, as questões sociais, culturais, educativas, científicas, políticas...). As grandes organizações políticas e económicas apropriaram-se do termo e hoje fala-se de cidades sustentáveis, de turismo sustentável, de empresas sustentáveis e de políticas sustentáveis, que ao fim e ao cabo, têm por missão manter o crescimento económico à custa de um ambiente progressivamente exaurido, comprometido e corrompido.

Se olharmos para aquilo que foram os Objetivos do Milénio e para os Objetivos do Desenvolvimento Sustentável (ODS) estabelecidos pela ONU, verificamos que dos 8 objetivos estabelecidos para 2015, apenas um tinha um significado efetivo de compromisso ambiental (sendo todos os restantes de carácter social e político): o objetivo $\mathrm{n}^{\circ}$ 7, "Garantir a sustentabilidade ambiental". Dos 17 ODS que guiam a política internacional entre 2015 e 2030, apenas 5 dizem diretamente respeito à relação economia-ambiente: os ODS 6 , relativo à água, 7 , relativo à energia, 13, relativo à ação climática, 14 , relativo à proteção da vida marinha, e 15 , relativo à proteção da vida terrestre.

Em síntese, as intenções são boas, mas as questões ambientais continuam a não ser individualizadas e a não ter o destaque que merecem, por serem integradas em políticas sociais e culturais importantíssimas, mas que a meu ver deveriam ser tratadas separadamente.

Moral de uma história que já vai longa: as expressões "desenvolvimento sustentável" e "sustentabilidade" perderam-se pela sua própria força e sentido. Os 
objetivos continuam a ser desenvolver, no sentido de crescer económica, social e culturalmente o que, se funcionasse, não deixaria de ser bom para todos e para cada um, em vez de tratar todos os elementos do ambiente de modo a cumprir o objetivo essencial "satisfazer as necessidades da geração presente sem comprometer a capacidade das gerações futuras para satisfazerem as suas próprias necessidades".

\section{As dimensões da Gestão Ambiental e uma visão sistêmica}

Jorge Pinto Filho - Prof. Lúcio Cunha, dentro dos componentes deste arcabouço da gestão ambiental, têm o diagnóstico ambiental, planejamento ambiental e gerenciamento ambiental. Isto posto gostaria que você relatasse qual sua compreensão por estas dimensões?

De facto, hoje a preocupação ideológica e científica com a Ambiente, assume também uma dimensão técnica. Em Portugal, apesar de não haver empregabilidade absoluta, quase todas as Universidades têm cursos de Mestrado Integrado em Engenharia do Ambiente, demonstrando o interesse social que as questões técnicas ligadas à gestão do Ambiente assumem. Para além destes, há muitas outros licenciaturas de Ensino Superior nas áreas do Ambiente, sejam eles ligados ao mar, à saúde, à energia, ao património ou mesmo à gestão. Cursos de mestrado e de doutoramento são também muitos e, por exemplo, na área da Geografia, ciência que podemos considerar de charneira entre a Sociedade e o Ambiente, na nossa Universidade de Coimbra, temos um curso de Mestrado que se intitula "Geografia Física, Ambiente e Ordenamento do Território".

No plano da investigação científica, na Unidade de I\&D que junta investigadores da área da Geografia das Universidades de Coimbra, Porto e Minho, dos três grupos de trabalho temático que possui, o primeiro tem como tema: Natureza e Dinâmicas Ambientais, numa preocupação clara dos estudos de Geografia Física sobre as questões ambientais.

A estes cursos superiores de formação inicial e a este exemplo ao nível da investigação poder-se-iam juntar muitos outros em que para além, das questões mais gerais do ambiente são tratados temas mais específicos (ecologia, biodiversidade, geodiversidade, alterações climáticas, gestão da água, dos esgotos e dos resíduos, entre muitos outros). São apenas exemplos muito difusos da importância que as questões ambientais assumem na formação superior teórica e 
técnica e, depois, na investigação científica de carácter mais fundamental ou mais aplicado.

Tendo em consideração o modo sequencial como a questão é formulada, diagnóstico, planeamento e gerenciamento, eu diria que estas três componentes do processo de gestão ambiental estão presentes nas preocupações governamentais e da sociedade civil, através do modo como se fazem, por exemplo os estudos de impacte ambiental necessários para a realização de grandes obras públicas ou privadas ou os estudos de ordenamento do território a diferentes escalas (do nacional ao local). A minha formação de geógrafo diz-me que nestes estudos e noutros (como por exemplo, os relacionados com a gestão dos riscos naturais e ambientais) somos melhores a fazer o diagnóstico que a prever e a planear e futuro e, sobretudo, a fazer o gerenciamento (entendido no sentido do acompanhamento efetivo dos resultados das obras ou dos planos em causa). Neste último aspecto, falta ou dá-se menor importância, muitas vezes, à realização dos trabalhos de monitorização necessários para o acompanhamento e correção de funcionamento das obras ou dos planos em que se enquadram.

\section{A operacionalização da Gestão Ambiental e a tomada de decisões}

Jorge Pinto Filho - Prof. Lúcio Cunha, a operacionalização das dimensões de Gestão Ambiental se dá com adoção de instrumentos de forma integrada, como estes: padrões de qualidade ambiental, definição de áreas protegidas, cadastro de atividades poluidoras e usuárias dos recursos naturais, zoneamento ambiental, avaliação de impactos ambientais, licenciamento ambiental, recuperação de áreas degradadas, auditorias ambientais e penalidades ambientais. Desta forma, como você avalia a efetivação destas ferramentas?

Como já insinuei em respostas anteriores, pelo seu carácter holístico e sistêmico, pela interpenetração de escalas e pela relação que se estabelece entre ambiente e sociedade, os estudos ambientais são sempre complexos, têm um âmbito multidisciplinar, quando não mesmo transdisciplinar, e revestem-se, não raras vezes, de um carácter conflituoso. Por isso, nós temos uma legislação de qualidade, mas que nem sempre é fácil de aplicar em todos os graus da escala de intervenção sobre o ambiente e o território. Há muitas exceções ao zoneamento ambiental (mesmo em áreas protegidas), há licenças ambientais que são conseguidas por via judicial por má administração ambiental dos processos, há muitas recuperações ambientais que não são feitas porque as empresas 
responsáveis pela extração entretanto se dissolvem, e por aí fora... Muitas vezes no momento de decidir há que pôr nos pratos da balança a economia (emprego, exportações, contribuição para o PIB) e os elementos ambientais prejudicados (água, ar; vida) e aí "esquece-se" a tal sustentabilidade, a favor da dita "economia real".

Sob este pano geral, claro que a pluridisciplinaridade é, por vezes conflituosa, e a mesma coisa acontece com a organização político-administrativa dos poderes públicos responsáveis.

Costuma dizer-se que, em Portugal, existem para algumas áreas temáticas da vida pública demasiados responsáveis. É o que parece acontecer com uma das áreas mais sensíveis do ponto de vista ambiental, como é o caso das chamadas zonas costeiras. Sobre as zonas costeiras e sobre aquilo que nelas se implanta ou se realiza têm jurisdição a APA (Agência Portuguesa do Ambiente, diretamente dependente do Ministério do Ambiente), as CCDR (Comissões de Coordenação e Desenvolvimento Regional) e as Câmaras Municipais, mas também entidades responsáveis pelas pescas, pelos portos, pela Marinha, pelo Turismo, pela Proteção Civil e talvez ainda mais algumas que não me ocorrem de momento. Facilmente se calcula a dificuldade de articulação na produção de documentação e, sobretudo, da tomada de decisão em tempo útil e eficaz.

\section{Pesquisas multidisciplinares: uma coexistência integralizadora}

Jorge Pinto Filho - Prof. Lúcio Cunha, diante de uma matriz eclética de ferramentas de gestão ambiental, observa-se um cenário que exige a necessidade de uma visão sistêmica da sociedade, com isso, surgem as pesquisas multi, inter e transdisciplinares. Desta maneira, qual sua opinião sobre pesquisa desta natureza?

O ecletismo dos instrumentos de gestão ambiental é uma necessidade que decorre da complexidade e do carácter geossistémico do ambiente. Os estudos ambientais e, particularmente, a análise e a aplicação destes instrumentos necessitam, assim, de uma abordagem multidisciplinar que seja capaz de compreender integralmente o ambiente, enquanto sistema aberto e sujeito a múltiplas forças e influências que lhe são exteriores.

No entanto, a abordagem técnica em regra faz-se através de pequenas equipas, quando não mesmo de técnicos isolados, num conjunto de práticas que ignoram as leituras diferentes da natureza e da sociedade, ou seja, que aplicam um conjunto de regras pré-estabelecidas e a que falta, pelo menos nos casos mais 
complexos, uma análise científica, capaz de trazer para a análise outros dados, outras previsões e outras propostas desenhadas à medida de cada situação.

No caso português, acresce ainda um outro problema que é o de atribuir aos "donos da obra" a responsabilidade de realizar, por exemplo, os Estudos de Impacte Ambiental, o que, nalguns casos, pode enviesar o estudo apontando determinadas direções de análise e esquecendo outras, conforme os interesses em causa. $E$ as análises e avaliações a seguir feitas acabam por ficar de alguma forma condicionadas. E não se pense que a questão se coloca apenas com as obras resultantes de investimentos privados ou com aquelas que têm maior dimensão...

A falta de interdisciplinaridade leva a que também os focos de análise sejam, nalguns casos, desajustados às questões ambientais em causa. Por exemplo, questões ligadas às modificações da paisagem ou a modificações na evolução dos sistemas naturais abióticos, bem como questões relacionadas com as transformações socais e culturais das comunidades, são em regra preteridas, pela maior atenção dada às questões ecológicas e/ou às questões de poluição direta.

\section{A Função da Universidade no Século XXI}

Jorge Pinto Filho - Prof. Lúcio Cunha, perante estas transformações na sociedade e, com o surgimento de pesquisas multi, inter e transdisciplinares, bem como acentuação de pesquisas mais disciplinares, na sua opinião qual a função da Universidade no Século XXI?

Como não podia deixar de acontecer, as transformações da Sociedade chegam às suas instituições e, naturalmente, também às suas Universidades. Por vezes as próprias instituições de Ensino Superior são (ou deveriam ser) os principais instigadores ou mesmo os obreiros destas mudanças. Trabalho na Universidade há tempo suficiente para ter podido assistir a algumas modificações no que à Universidade de Coimbra diz respeito.

Penso que nos últimos 40 anos essas modificações aconteceram em dois sentidos: o principal diz respeito ao reforço do carácter aplicado da investigação e, com ela, também do ensino que se realiza. A investigação aplicada, importante por devolver à sociedade uma parte daquilo que a Universidade dela recebe do ponto de vista económico, social e cultural, é também um importante modo de obtenção de financiamentos individuais e para as equipas de trabalho.

Outra, mais brusca e mais recente, pelo menos no caso das Faculdade de Ciências Sociais, como acontece com a minha Faculdade de Letras, tem a ver com 
a globalização (anglófona) das métricas de publicação individuais (de cada um dos investigadores/professores) e coletivas (das Unidades de Investigação), que traz de facto, as vantagens de uma troca de dados e de resultados à escala global, mas que introduz também alguns vícios de normalização de temas e de metodologias de trabalho que retiram grande parte da liberdade e da criatividade que caracterizam a investigação universitária.

$\mathrm{Na}$ Universidade de Coimbra, os estudos ambientais estão em várias faculdades e áreas do saber, da Ecologia à Geografia, da Arquitetura à Sociologia, das Ciências da Saúde à Engenharia. O ambiente, as alterações climáticas, os ambientes naturais, a evolução da linha de costa, as áreas protegidas, os ambientes urbanos são áreas de trabalho que têm crescido, que se têm aprofundado e que têm sido alvo de projetos de investigação e de prestação de serviços maiores ou menores, de carácter interdisciplinar. Por vezes as iniciativas interdisciplinares partem dos investigadores, mas também em muitos casos são incentivadas e dirigidas pelas estruturas universitárias.

Outro aspecto importante tem a ver com a inserção ou com a integração na vida universitária das preocupações ambientais do mundo moderno, por exemplo através dos mecanismos de poupança de energia, de utilização de energias renováveis, de reciclagem de vários produtos consumíveis, de medidas diretas de mitigação das alterações climáticas, entre outras. Com estas medidas, a Universidade procura dar o exemplo e ajudar os estudantes a criar uma consciência ambiental, mas também vai dando contributos significativos para a mitigação de alguns problemas. $O$ passo mais recente foi a criação da página uc.pt/sustentabilidade que se enquadra no compromisso da Universidade de Coimbra para com os Objetivos de Desenvolvimento Sustentável da Agenda 2030 das Nações Unidas, mostrando os compromissos assumidos e monitorizando os resultados entretanto alcançados.

\section{O Ensino, Pesquisa e Extensão da Universidade no Século XXI}

Jorge Pinto Filho - Prof. Lúcio Cunha, as universidades obedecem ao princípio de indissociabilidade entre ensino, pesquisa e extensão, desta forma qual sua compreensão ao longo destes anos como a instituição "universidade" tem atuado nestas frentes?

Continuando a responder à questão anterior, à Universidade do século XXI compete investigar, ensinar e transferir conhecimento para diferentes sectores da 
sociedade, de modo a dar resposta a muitos dos problemas do mundo atual, de forma independente e rigorosa no plano científico. Na minha opinião os Professores Universitários são ou deverão ser investigadores que ensinam, pelo que o ensino deve ser mais baseado na investigação, do que um ensino teórico e de manuais, devendo também ser independente, rigoroso e pedagogicamente bem estruturado. Por isso, os estudantes, desde a sua entrada na Universidade, devem ser envolvidos nos projetos de investigação e de prestação de serviços, como método de aprendizagem através do "saber fazer". Para os estudantes de pós-graduação (mestrados e doutoramentos) estes procedimentos deveriam ser praticamente obrigatórios.

Claro que este processo nem sempre é fácil e nem sempre é bem conseguido. Será eventualmente mais fácil nas ciências naturais, nas ciências da saúde ou nas ciências da engenharia, do que nas ciências humanas e sociais. Mas esta tendência de fazer os estudantes participar nos processos de investigação é fundamental.

Como muitas outras, a Universidade de Coimbra vai um pouco mais longe e tem uma incubadora de empresas (o Instituto Pedro Nunes), onde professores, investigadores e alunos recentemente formados podem instalar e desenvolver pequenas empresas que estimulem o empreendedorismo individual e coletivo e preparem os estudantes que acabam de sair da Universidade para criar e desenvolver as suas próprias oportunidades de trabalho e de negócio. Algumas importantes empresas de alta tecnologia de Coimbra e da Região Centro foram aqui iniciadas.

\section{As Universidade Emergentes e o Desenvolvimento Regional}

Jorge Pinto Filho - Prof. Lúcio Cunha, você atualmente encontra-se em uma das universidades mais antigas e clássicas do mundo (a Universidade de Coimbra data de 1290) e de reconhecimento internacional, qual a mensagem você poderia passar para a comunidade acadêmica da UFERSA (A UFERSA data de 1960), na qual estou vinculado atualmente, no sentido de buscar esta posição de destaque?

De facto, a Universidade de Coimbra é uma das Universidades mais antigas da Europa, nascida em 1 de Março de 1290, o que significa que tem a 730 anos de idade. Mais do que reconhecimento nacional e internacional esta idade traz-lhe responsabilidade. Responsabilidade ao nível da qualidade e exigência do ensino, ao nível do rigor e da excelência da investigação que produz e ao nível do seu papel na 
construção de uma sociedade melhor, mais sábia e culta, mais livre, mais justa e com melhor qualidade de vida.

Estas e outras responsabilidades devem acompanhar o trabalho de todas as universidades, mais antigas ou mais novas, maiores ou mais pequenas, situadas em grandes metrópoles ou em pequenas cidades.

Hoje o Mundo ficou mais pequeno! E na ciência ainda mais que noutras áreas de atividade do ser humano. As facilidades de deslocação entre países, a Internet, a comunicação na "língua franca" que é o inglês, a internacionalização (por vezes mesmo globalização) das grandes editoras e empresas tecnológicas, fazem com que todas as Universidades, na China como nos Estados Unidos, na Europa como na América latina, em Portugal como no Brasil, pertençam (ou sejam obrigadas a pertencer) a este mundo global de Ciência que, como disse já antes, nos envolve a todos, nos puxa para cima, mas também nos classifica, nos hierarquiza, nos retira um pouco da imaginação criativa e nos afasta muito vezes dos nossos contextos locais e regionais.

Neste contexto, o que desejo para a UFERSA é exatamente o mesmo que quero para a UC: uma investigação exigente e rigorosa, que estimule um ensino exigente e de qualidade, um reforço e um caminho inequívoco de internacionalização, mas sempre com os pés bem assentes nos nossos territórios, no ambiente e na sociedade que nos são próximos, de modo a incluí-los como beneficiadores do conhecimento que criamos e das soluções que estudamos.

Por vezes, a globalização mais feroz, a competitividade nacional e internacional, os rankings em que estamos sempre a ser medidos, a necessidade de obtenção de financiamentos através de projetos, as relações pessoais nas estruturas de saber (nacionais e internacionais) e, porque não dizê-lo, a atitude mais proativa, mais assertiva ou apenas mais inteligente de alguns, fazem com que as universidades, ao evoluir e ao crescer, se diferenciem internamente e se afunilem em demasia, levando que algumas áreas se especializem, se internacionalizem, cresçam financeiramente e se desenvolvam num círculo vicioso de merecidas vantagens (as boas), enquanto outras têm mais dificuldade, marcam passo, centram-se mais no ensino que na investigação, perdem pessoal e mesmo a atratividade que têm sobre os alunos.

Se pensarmos que o termo Universidade se relaciona com Universalidade, neste caso do conhecimento, a verdadeira Universidade tem de levar as ciências humanas e sociais a par com a ciências naturais e exatas, tem de estabelecer 
regras de funcionamento que favoreçam a ciência, mas também a cultura, a saúde, mas também a filosofia, as tecnologias, mas também as artes. Equilíbrio entre Faculdades e cursos e colaboração interdisciplinar também são ferramentas importantes na Universidade do século XXI. Por isso as desejo para a UFERSA e para a UC.

\section{O Ensino na Universidade no Século XXI e sua responsabilidade cidadã}

Jorge Pinto Filho - Prof. Lúcio Cunha, na UFERSA venho atuando no Centro Multidisciplinar de Pau Ferros, em disciplinas de Ambiente, Energia e Sociedade; Direito Ambiental; Recuperação de Área Degradadas e; Sistema de Gestão Ambiental, sendo ofertada para diversos cursos (Arquitetura e Urbanismo, Ciência e Tecnologia, Engenharia Ambiental e Sanitária e, Engenharia Civil), com isso, percebe-se que é uma atuação predominantemente na área ambiental. Diante dos anos de sua experiência na docência na área geografia e afins (neste caso ambiental também), o que diria a um jovem que estaria iniciando sua formação acadêmica neste campo do conhecimento?

$\mathrm{Na}$ Geografia ou noutras áreas científicas que estudam as relações entre a Natureza e a Sociedade, que trabalham sobre o ambiente e os territórios, trabalho não falta. Como se costuma dizer, pode faltar o financiamento, mas não falta trabalho para fazer, tão preocupantes são as agressões antrópicas sobre a natureza e o ambiente, tão fortes são os impactes ambientais das principais políticas e ações produtivas, tão prejudiciais são as manifestações de riscos naturais e ambientais com que a sociedade de hoje é brindada.

Em regra, na área da Geografia e em muitas outras estamos ainda naquilo que poderíamos chamar uma fase inicial dos estudos ambientais, a fase das caracterizações territoriais, das sínteses ambientais e das listagens de preocupações. Naturalmente que esta fase dos estudos que tem a ver com 0 conhecimento da situação atual é importante, mesmo crucial, mas é necessário ir mais além. É necessário estudar os impactes das ações e das políticas públicas sobre o ambiente e sobre a Natureza, assim como é necessário reforçar os estudos dos riscos naturais e antrópicos, tendo em conta não apenas as manifestações dos processos perigosos (sismos, vulcões, cheias, incêndios, pandemias), mas também as vulnerabilidades das populações e dos territórios que a estes processos perigosos estão sujeitos. É fundamental trazer as novas tecnologias para estes estudos e, portanto, juntar a quantificação à descrição, a modelação à 
caracterização, reforçando a análise, espacializando-a e dotando-a de um carácter preditivo.

Nestes processos, o mapa é fundamental para caracterizar, para mostrar os efeitos e para prever cenários e consequências. O mapa, a principal ferramenta da Geografia, tanto para trabalho de base como para tradução dos resultados, é também um dos principais elementos para a prática interdisciplinar e para a gestão territorial e ambiental. Com o mapa o "porquê" passa a mostrar o "como" e o "quando" passa a incluir o "onde", de modo a que as projeções de futuro sejam interpretadas de modo diferenciado no espaço em que se inscrevem. O exemplo dos múltiplos estudos da pandemia que estamos a viver, mostra claramente o papel do mapa e a importância da Geografia (e dos estudos ambientais) na interpretação espacial dos casos, na gestão das crises e na implementação de medidas de prevenção.

Em síntese, os estudos ambientais estão a reforçar-se, o seu carácter tenderá a ser cada vez mais específico e proativo, mas também mais interdisciplinar e as novas tecnologias de cartografia e de modelação espacial cada vez mais uteis nestes processos.

\section{A Pesquisa na Universidade no Século XXI e a preocupação com a humanidade}

Jorge Pinto Filho - Prof. Lúcio Cunha, venho atuando na pesquisa através o Grupo de Grupo de Estudos em Ciências Ambientais do Semiárido - GECIAMS, sendo desenvolvida com apoio da UFERSA, na qual mantenho parceria a UERN, sendo membro permanente do Programa de Pós-Graduação em Planejamento e Dinâmicas Territoriais do Semiárido - PLANDITES, atuando na linha de pesquisa de Dinâmicas Territoriais no Semiárido. Diante estes anos de sua experiência na investigação científica em Natureza e Dinâmicas Ambientais, inclusive sendo o coordenador desta área de investigação junto ao CEGOT, quais diretrizes que recomendaria para um grupo de pesquisadores que estão iniciando sua atuação neste campo do conhecimento?

Numa entrevista tão longa, é difícil não haver algumas repetições nas ideias maiores.

A minha experiência é complexa, atravessou um tempo já suficientemente longo para ter assistido a algumas mudanças de paradigma na investigação científica, nos modelos de financiamento de projetos, no funcionamento de redes 
nacionais e internacionais, na seleção de temas de investigação e na constituição e distribuição de tarefas para os trabalhos em equipa, para citar apenas alguns dos problemas correntes na organização de uma unidade de investigação.

Não há modelos perfeitos, mas parece haver algumas regras gerais: trabalho em projeto e em equipas interdisciplinares; escolha de temas especializados e "ganhadores", em detrimento de temas muito gerais e apenas agregadores das vontades individuais dos membros das equipas; utilização metodológica de novas tecnologias; estabelecimento de metas; apoio em consultores especializados. Estes são alguns dos princípios gerais, mais fáceis de dizer e de escrever que de cumprir. Seguem-se a articulação entre a investigação pura e alguma prestação de serviços que dela possa resultar, entre investigação e o ensino, bem como a incorporação de estudantes nas equipas.

Não quero parecer paternalista na indicação de ideias que todos temos na cabeça! Apenas reflito sobre muito daquilo que nos tem escapado, no nosso CEGOT, e que tem de ser conseguido para que os mais novos possam vir a ter condições de trabalho pelo menos semelhantes aquelas que eu encontrei (princípios da sustentabilidade aplicados à investigação?). Mas não é fácil, porque em tempos de forte liberalização da economia e da vida universitária, permanecem e reforçamse mesmo algumas contradições da vida académica, particularmente na investigação que é hoje muito mais competitiva, menos livre e mais condicionada economicamente que há 40 ou 50 anos.

\section{A Extensão na Universidade no Século XXI e a inclusão social}

Jorge Pinto Filho - Prof. Lúcio Cunha, a atuação de um professor universitário a cada dia precisa ser mais conectada com a sociedade, com isso, a partir das funções da Universidade, em produzir conhecimento, formar profissionais e intervir na sociedade, gera uma expectativa de mudança social. Desta forma, com base em sua interação com múltiplas organizações da sociedade, inclusive sendo membros de sociedades, academias e órgãos, qual a postura que indicaria para jovens professores que ainda estão buscando inserir nessas conexões?

A Universidade do século XXI, embora tenha sempre por missão principal o Ensino, está muito assente na Investigação e na Transferência de Conhecimento para a Sociedade. "O Professor Universitário é um investigador que ensina" e que partilha (por vezes diz-se "devolve") com a Sociedade o conhecimento que 
conseguiu produzir através dos meios financeiros, materiais e culturais que esta colocou ao seu alcance.

Ainda que, em minha opinião, os processos de transferência de saber das Universidades para a Sociedade estejam fortemente inquinados pelas regras do mercado, que fazem com que estes processos sejam muitas vezes realizadas a nível individual ou de pequenos grupos, em vez de envolverem diretamente as Unidades de Investigação e as Faculdades, com criação de equipas interdisciplinares e internacionais, ou pela competição, de certo modo ilegítima, entre grupos de investigação universitária e empresas de investigação, o facto é nunca como hoje, os processos de transferência do saber ou as atividades de extensão para a sociedade tiveram uma dimensão e importância científica, económica e social tão significativas. E os estudos sobre o Ambiente não são exceção, nesta matéria.

Particularmente, nos Departamentos ou Unidades de Investigação ligados à Geografia e aos Estudos Territoriais, a produção de conhecimento de professores e alunos, através sobretudo das dissertações de mestrado e das teses de doutoramento, mais do que permitir o avanço do conhecimento, pode assentar em casos concretos de estudo, na resolução de casos específicos e na transferência social dos resultados.

A minha recomendação vai pois para o trabalho em equipa e para a articulação do trabalho teórico ("não há nada de mais aplicado que uma boa teoria") com o seu desenvolvimento aplicado, sempre que possível feito em articulação com o mercado.

Outra recomendação, mais para o meu país que para o Brasil, é a de que os estudiosos do ambiente (engenheiros, geógrafos, biólogos, sociólogos, gestores ambientais), os mais jovens e os mais velhos, os universitários e os não universitários, tenham uma maior participação nos "media" e, particularmente, nas televisões e na internet, discutindo e debatendo as grandes questões ambientais do mundo atual (alterações climáticas, riscos, desmatamento, desertificação, degradação dos ambientes urbanos, segregação social, poluição das águas, dos solos e do ar, saúde pública). Na discussão pública que é feita todos os dias são sempre os mesmos a debater (políticos ou aprendizes de políticos, jornalistas, membros de associações ambientalistas) e os debates são sempre simplificados, por vezes mesmo simplistas, previsíveis, a procurar mais a polémica que o entendimento, mas quase sempre sem informação fidedigna, cheios de "fake news" ou de "fake data" e de teorias de "ouvir dizer". Como todos sabemos e proclamamos, o tempo que vivemos é um tempo de informação, mas terá de ser um tempo de 
informação séria, fundamentada e argumentada por quem sabe. Se quem verdadeiramente sabe se esconde ou pelo menos se cala, fica o espaço aberto à informação incompleta, vulgar, tendenciosa e, por vezes, falsa. E aqui todos podemos ajudar, saindo do conforto dos nossos livros, dos nossos computadores e dos nossos laboratórios.

A sociedade e a natureza a que pertencemos merecem esse esforço!

\section{Finalmente o que não foi dito...}

Jorge Pinto Filho - Por fim, Prof. Lúcio Cunha, certamente existem debates importantes das quais nós falamos, mas existem também outros importantes que eu posso ter me esquecido de perguntar. Assim, gostaria que você usasse este espaço justamente para falar de temas importantes das quais nós não falamos.

Ainda que a entrevista já vá longa, há sempre mais coisas para dizer e eu gostaria de terminar com duas referências mais:

- A primeira tem a ver com a relação entre a Natureza e a Sociedade nos estudos ambientais. Na minha qualidade de geógrafo, tenho dado conta da enorme importância em estudar e interpretar a Natureza, a biodiversidade e a geodiversidade que a integram numa perspectiva social e, mesmo, cultural, que lhe dá muito mais sentido. Pensando apenas em dois dos principais aspectos ambientais estudados pela Geografia, os recursos e os riscos naturais, essa leitura leva-nos a procurar caminhos em áreas como as do turismo e do lazer, no caso dos recursos geopatrimoniais, e nas áreas das vulnerabilidades e desigualdades sociais, quando procuramos entender os impactos efetivos das manifestações dos riscos naturais. Como digo muitas vezes aos meus alunos, para estudar estes fenómenos de modo completo e integrado, para nos aproximarmos de interpretações que tenham verdadeira aplicabilidade, as Ciências Naturais (da Terra e da Vida) ganham mais relevo quando lidas em conjunto com as Ciências Sociais e da Cultura. E, deixemos, por enquanto, de lado o significado económico da Natureza! Assim, Natureza e Sociedade, Ciências da Terra e Ciências Sociais sempre serão nos estudos ambientais as duas faces de uma mesma moeda.

A Geografia, nas suas vertentes de Geografia Física e de Geografia Humana, deveria pois estar no lugar cimeiro dos estudos ambientais. No entanto, talvez por imperativos de uma espacialização exacerbada e com procura de métodos de outras áreas científicas, questões que estão relacionadas, entre muitas outras coisas, com a necessidade de publicação em revistas internacionais indexadas, enfraquece-se a 
já débil articulação entre Geografia Física e Geografia Humana e desvalorizam-se nos estudos ambientais, mesmo feitos na área da Geografia, o espaço, o território e as paisagens como objetos de análise e de intervenção fundamentais.

\section{Considerações Finais}

Quero, muito vivamente, agradecer ao meu colega e amigo Jorge Pinto Filho, da UFERSA, esta oportunidade para que, ao responder a esta entrevista, tenha podido refletir sobre a Geografia que tenho vindo a fazer, aquela que gostaria de ter feito e que ficou pelo caminho, bem como a perspectivar algumas linhas de futuro.

Agradeço-Ihe também a possibilidade de refletir sobre os contextos universitários de Portugal e do Brasil, bem como sobre a sua inserção neste mundo do século $X X I$, fortemente globalizado, competitivo e territorialmente muito injusto.

Agradeço-Ihe, finalmente, por esta conversa sobre questões ambientais que, de um lado e do outro do Atlântico, são aparentemente tão diversas, mas na realidade tão semelhantes.

Tenho tido a sorte e a felicidade de nos últimos 25 anos ter participado em muitas discussões, mais temáticas ou mais genéricas, mas sempre muito produtivas, como colegas brasileiros. Visitámo-nos, investigámos em conjunto, discutimos ideias e, sobretudo, fizemos amizades. A amizade não se agradece, Jorge Pinto Filho, mas acredita que foi muito gratificante este tempo da nossa colaboração, apesar de alguns condicionamentos de tempo e de lugar (coisas da Geografia).

Finalmente, gostaria de referir uma ideia que tem vindo a ser desenvolvida por geógrafos e especialistas afins de Portugal e do Brasil, a ideia de fazer acompanhar todo o trabalho de investigação científica publicada em inglês e feita para o mundo global e globalizado, de uma Geografia feita em Português, que nos acolha a nós, portugueses e brasileiros, mas que envolva também moçambicanos, angolanos, guineenses, cabo-verdeanos e todos os que por esse mundo fora falam e escrevem em Português. O mundo da Geografia e dos estudos sobre o ambiente precisam também desta valorização. Afinal, graças ao trabalho científico que se faz no Brasil, a língua portuguesa é a terceira mais utilizada em Ciência (depois do Inglês e do Chinês). 


\section{NOTAS DE AUTOR}

\section{CONTRIBUIÇÃO DE AUTORIA}

Jorge Luís de Oliveira Pinto Filho - Concepção. Elaboração da entrevista. Organização, revisão e aprovação da versão final do trabalho.

\section{FINANCIAMENTO}

Financiamento Interno da Universidade Federal Rural do Semi-Árido - UFERSA

Financiamento Interno da Universidade de Coimbra - UC

\section{CONSENTIMENTO DE USO DE IMAGEM}

Não se aplica

\section{APROVAÇÃO DE COMITÊ DE ÉTICA EM PESQUISA}

Não se aplica.

\section{CONFLITO DE INTERESSES}

Informar conflitos de interesse: financeiros, pessoais, entre possíveis revisores e editores, possíveis vieses temáticos. Para mais informações: https://www.abecbrasil.org.br/arquivos/whitepaper_CSE.pdf

\section{LICENÇA DE USO}

Este artigo está licenciado sob a Licença Creative Commons CC-BY. Com essa licença você pode compartilhar, adaptar, criar para qualquer fim, desde que atribua a autoria da obra.

\section{HISTÓRICO}

Recebido em: 21-04-2021

Aprovado em: 20-08-2021 